\title{
Person and number syncretisms in Dutch
}

\author{
Suzanne Aalberse $\cdot$ Jan Don
}

Received: 18 July 2009 / Accepted: 22 September 2009 / Published online: 26 June 2010

(C) The Author(s) 2010. This article is published with open access at Springerlink.com

\begin{abstract}
The aim of this paper is to make sense of the typologically quite exceptional pattern of person neutralization in the plural as we find it in Dutch verbal paradigms. We argue that Dutch, and most of its dialects, have a structural pattern of syncretism in their verbal paradigm: there are no person-distinctions in the plural. The main question of this paper is: where does this structural pattern of neutralization in Dutch come from, if we cannot explain it as a typologically wellattested pattern? As a first step, note that although the pattern is typologically quite odd, it conforms to another well-known generalization about paradigms: neutralization occurs in the marked half of the paradigm (see e.g. Nevins 2009). Further, we need to explain why this pattern occurs precisely in the Netherlands at this particular point in time. To this, we argue that this pattern arises as the result of a particular language acquisition strategy together with reduced evidence from the input for the fully inflected forms, probably as a result of dialect contact. This reduced evidence causes the third person, being the most frequent form, to dominate the other plural forms. In combination with limited paradigm splitting (Pinker, 1996), this explains the uniform plural that we find in most Dutch dialects.
\end{abstract}

Keywords Inflectional paradigm - Morphological neutralization ·

Dialectal variation $\cdot$ Language change

S. Aalberse $(\bowtie) \cdot$ J. Don

Amsterdam Centre for Language and Communication, Universiteit van Amsterdam,

Spuistraat 134, 1012 VB Amsterdam, The Netherlands

e-mail: s.p.aalberse@uva.nl 


\section{Introduction}

The aim of this paper is to make sense of the typologically quite exceptional pattern of person neutralization in the plural as we find it in Dutch verbal paradigms. We will first argue that Dutch, and most of its dialects, have a structural pattern of syncretism in their verbal paradigm: there are no person-distinctions in the plural.

$$
\begin{array}{lll} 
& \text { singular } & \text { plural }^{1} \\
1^{\text {st }} \text { person } & \text { klop } & \text { klopp-en } \\
2^{\text {nd }} \text { person } & \text { klop-t } & \text { klopp-en } \\
3^{\text {rd }} \text { person } & \text { klop-t } & \text { klopp-en }
\end{array}
$$

This pattern is typologically quite odd. Noyer (1992) posits a universal featurehierarchy in which [person] is in a higher position than [number]. This seems to imply that if these two features are morpho-syntactically present on the same node, and during spell-out one of the two features has to give way for whatever reason, the hierarchy predicts that it is [number] rather than [person] that would be left unexpressed. This seems to make the correct prediction for a large number of languages.

Similarly, it has been observed by Cysouw (2003, p. 300) that complete neutralization of person in the plural is rare, mentioning only six languages, including Dutch. On the other hand, Cysouw shows that absence of number marking in the context of person is common.

Cysouw accounts for this observation by relying on the so-called Animacy hierarchy (Corbett 2000, p. 56) given in (2):

(2) Animacy hierarchy

$1>2>3>$ kin $>$ human $>$ animate $>$ inanimate

According to this hierarchy, 'first person' is the 'most animate' of a number of categories, whereas 'inanimate' is the 'least animate' category. The more animate a particular category is, i.e. the higher its position on the Animacy hierarchy, the more likely it becomes that the category in question can be pluralized. The hierarchy is of the well-known implicational type. Thus, it may account for the fact, among other things, that if we find neutralization of number in second person pronouns, we will also find it in third person pronouns and all other categories lower in the hierarchy. Whereas, if we find neutralization in a lower category, that will not tell us anything about the possible neutralization of a higher ranked category.

Although neutralization of number in third person is typologically most common, there are diachronic studies of individual languages that show a different pattern. Let us first consider deflection in the Southern Oceanic language of Anejom as described by Lynch (2000, pp. 91-95) [as cited in Baerman et al. (2005, p. 73)], here shown in (3):

\footnotetext{
${ }^{1}$ The $-\mathrm{e}$ in the plural suffix stands for schwa. First person singular is marked by $-\varnothing$.
} 
(3)

Anejom aorist auxiliary

\begin{tabular}{lll}
\hline \hline & $19^{\text {th }}$ century & $20^{\text {th }}$ century \\
1 singular & ek & ek \\
2 singular & na & et \\
3 singular & et & \\
1 inclusive dual & intau & \\
1 dual & ecrau & \\
2 dual & ekau & \\
3 dual & erau & era \\
1 inclusive trial & intaj \\
1 trial & ektaj/ektij & \\
2 trial & ahtaj & \\
3 trial & ehtaj & \\
1 inclusive & inta \\
1 plural & ecra \\
2 plural & eka \\
3 plural & era &
\end{tabular}

In (3) we observe that the distinctions dual, trial and inclusive are lost in twentieth century Anejom. In all contexts but the singular, person marking is neutralized.

Two points should be made with respect to the patterns of deflection in Anejom and Dutch. First, the feature [singular] is considered the unmarked value for number whereas other values (such as [plural], [dual]) are more marked (Aikhenvald and Dixon 1998, p. 59; Baerman et al. 2005, pp. 92-95; Cysouw 2003, p. 309; Harley and Ritter 2002, p. 497). Marked features are more likely to cause neutralization of other categories than unmarked features. Nevins (2009, pp. 7-8) refers to the tendency of marked features to cause neutralization in other categories as MarkedTriggered Neutralization as formalized in (4).

(4) Markedness-Triggered Neutralization for a marked feature $m \mathrm{~F}$ and its unmarked counterpart $u \mathrm{~F}$

A feature $[+/-\mathrm{G}], \mathrm{F} \neq \mathrm{G}$, is not distinguished in the presence of $m \mathrm{~F}$ although it is distinguished in the presence of $u \mathrm{~F}$. 
The absence of person marking in the plural in Dutch and Anejom fits in with this more common pattern of Markedness-Triggered Neutralization: It is the marked value [plural] rather than the unmarked [singular] that defines the context of neutralization.

Second, both in Anejom and Dutch the 'dominant' form, i.e. the form that remains after neutralization, is the third person (plural). We claim that this is not coincidental but follows from the relative frequency of the third person with respect to the other forms in the plural.

We will now first discuss the Dutch data that lead us to conclude that indeed there is a structural pattern of person neutralization in the plural (Sect. 2). This leads us to the main question of the paper: where does this structural pattern of neutralization in Dutch come from, if we cannot explain it as a typologically well-attested pattern? In Sect. 3, we will argue that this pattern may arise as a result of language acquisition strategy together with less evidence from the input for the fully inflected forms, probably as a result of dialect contact. We argue that during acquisition in such contact-situations, language learners do not encounter sufficient evidence for separate second person plural forms. In combination with certain assumptions with respect to acquisition from Pinker (1996), involving limited paradigm splitting, we explain the uniform plural that we find in most Dutch dialects.

\section{Neutralization of [person] in the [plural]}

In this section we discuss dialectal variation in inflectional patterns as described in the Morphological Atlas of Dutch and Frisian dialects (henceforth: MAND). We show that, despite the wide range of variation in the inflectional patterns, the neutralization of person markings in the plural is widespread. The data are taken from the online version of the MAND (Goeman-Taeldeman-Van Reenen Project 1980-1995). The dialect maps were created with the use of the DynaSAND (Barbiers et al. 2006). ${ }^{2}$ The MAND includes data from 560 villages, towns and cities in the Dutch-speaking area in the Netherlands, Belgium and France. In addition, the MAND includes data from 53 Frisian dialects. In the MAND, the full inflectional paradigm is described for 8 verbs, namely: krijgen ('to receive'), zijn ('to be'), hebben ('to have'), doen ('to do'), kloppen ('to knock'), leven ('to live'), breken ('to break') and zwijgen ('to remain silent'). From the list above, leven ('to live') and kloppen ('to knock') are the only two regular verbs. Since we were looking for patterns of neutralization, and since infrequent verbs tend to deflect faster than frequent verbs (cf. Coveney 2000) we decided to select an infrequent regular verb. Moreover, we are interested in a general, regular system of person and number markings that applies to a large group of verbs. Verbs that are used frequently are more likely to go through item-specific changes which are unrelated to the general inflectional patterns. The verb-subject combination laten we ('let us'),

\footnotetext{
${ }^{2}$ The Morphological Atlas of Dutch dialects, also referred to as the Goeman-Taeldeman-Van Reenen Project, can be accessed through: http://www.meertens.knaw.nl/mand/database. We used the updated version (August 2009). The Dynasand can be accessed through http://www.meertens.knaw.nl/sand/.
} 
for example, can be reduced to lawe in the spoken language. This formal reduction is an item-specific change that we can relate to the high frequency of the verb-subject combination laten we ('let us'). The formal reduction occurs independent of the relation between other finite forms of the verb laten. Since we are interested in general inflectional paradigms in, we are not concerned with these types of item-specific change. Aalberse (2009, pp. 143-144) shows that kloppen ('to knock') has the lowest frequency of verbs described in the Morphological Atlas of Dutch dialects.

\subsection{Absence of person marking in Dutch dialects}

Most Dutch dialects exhibit at least some person marking in the singular. We assume the existence of the following features: $[ \pm S]$, where $[+S]$ has the interpretation "can be identified through the speaker". Furthermore, the feature $[ \pm U]$, where $[+\mathrm{U}]$ has the interpretation "can be identified through the utterance" (cf. Kerstens 1993). Moreover, we also assume the redundancy rules (5a) that rule out the non-existing combination $*[+\mathrm{S},-\mathrm{U}]$ and $*[-\mathrm{S},+\mathrm{U}]$. These two features and the redundancy-rules give us the person-markings in $(5 \mathrm{~b})$ :

$$
\begin{array}{llll}
\text { a. } & {[+\mathrm{S}] \Rightarrow} \\
& {[-\mathrm{U}] \Rightarrow} & {[+\mathrm{U}]} \\
& & \\
\text { b. } & {[+\mathrm{S}]} \\
& {[-\mathrm{S},+\mathrm{U}]} & \text { " } 1^{\text {st }} \text { person" } \\
& {[-\mathrm{S}]} & \text { " } 3^{\text {rd }} \text { person" } \\
& {[-\mathrm{S}]}
\end{array}
$$

If we look again at the paradigm for the present tense in (1), we can now give the following analysis, using Distributed Morphology (Halle and Marantz 1993; Halle 1997) as our theoretical framework [see also Bennis and MacLean (2006, p. 304)]. We assume that Dutch has an agreement node, which is spelled out according to the following rules of Vocabulary Insertion (henceforth: VI):

(6) AGR:

$$
\begin{array}{lll}
\text {-en } & \Leftrightarrow & \text { [plur] } \\
-\mathrm{t} & \Leftrightarrow & {[-\mathrm{S}]} \\
-\varnothing & \Leftrightarrow & {[+\mathrm{S}]}
\end{array}
$$

However, as has been argued in Aalberse and Don (2009), the rules in (6) cannot account for the neutralization of person features in the plural being a structural paradigmatic property of many Dutch dialects. The rules in (6) treat the neutralization as a more or less accidental (lexical) property of the Vocabulary Items. Aalberse and Don (2009) argue that, since the neutralization is so wide-spread, that apart from the VI's in (6), Dutch also hosts an Impoverishment rule, such as (7), that wipes out any person distinctions in the plural:

(7) $[\alpha \mathrm{S}, \beta \mathrm{U}] \rightarrow \varnothing /$ [plural] 


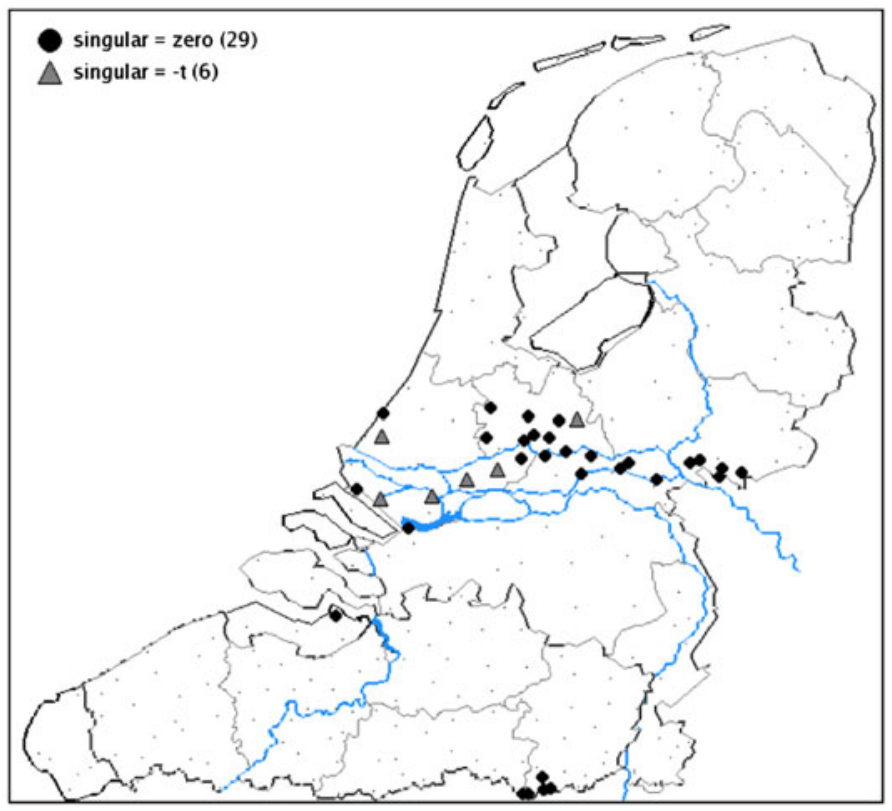

Fig. 1 Absence of person marking in the singular

Apart from dialectal evidence, Aalberse and Don (2009) also point out that highly irregular verbs (such as the verb zijn 'to be') having different person markings in the present (and past) tense, also have a uniform plural, thus underlining the independence of the neutralization from any specific Vocabulary Item.

Let us now consider the person-number markings, found across the Dutch-spoken area. The most common distinction in person markings attested is the distinction between first person on the one hand, and second and third on the other. Person marking is fully absent in the singular in only 35 measure points in the Dutch spoken area, as shown in Fig. 1.

Of these 35 dialects $^{3}, 29$ mark all singular forms with a zero-affix, and six mark singular forms uniformly with $-t$. So, these dialects can be analyzed as in (8a) and (8b) respectively:
a. $[-$ plur $] \Leftrightarrow-\varnothing$
$[+$ plur $] \Leftrightarrow$-en
b. $[-$ plur $] \Leftrightarrow-$ t
$[+$ plur $] \Leftrightarrow-$ en

\footnotetext{
${ }^{3}$ We will use the term 'dialect' here in reference to 'measure point'; we acknowledge that it is very well possible (and certainly often the case) that more than one measure point may refer to a single dialect. However, this usage seems common among dialectologists. Hence, our use of this terminology.
} 


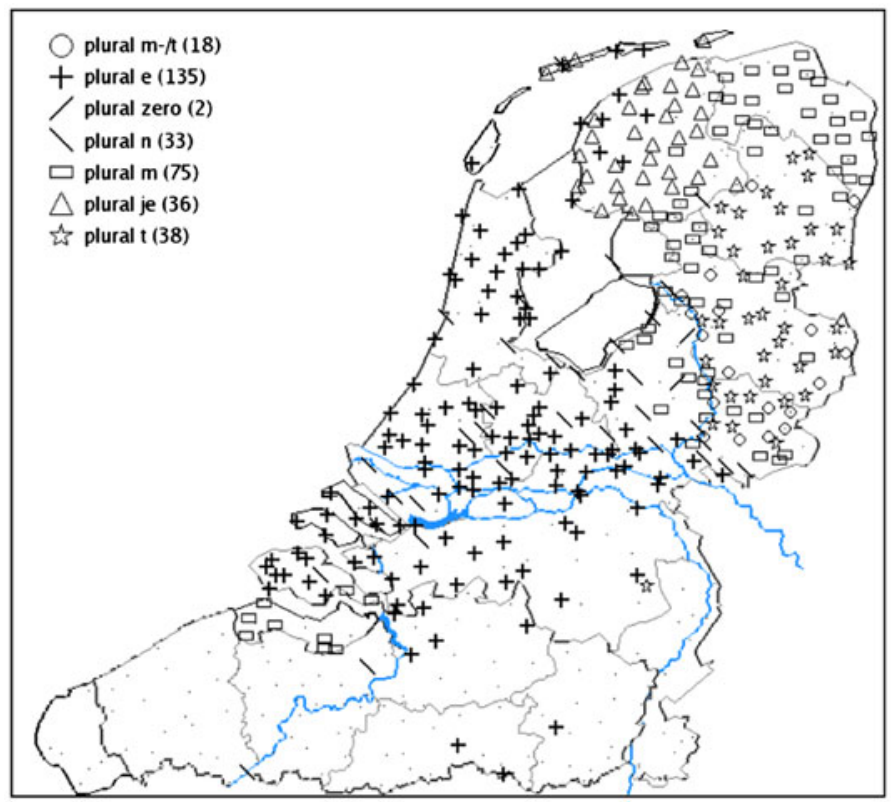

Fig. 2 Absence of person marking in the plural

In 30 measure points where person marking is absent in the singular, person is not encoded in the plural either. ${ }^{4}$

As predicted by Markedness-Triggered Neutralization, absence of person marking in the marked plural is much more common than in the unmarked singular. Figure 2 shows the measure points where person marking is absent in the plural. Person marking is absent in the context of the plural in 337 measure points $(65 \%)$. Person marking in the plural is present in 183 measure points (35\%) all located in the South. For the other measure points the data are not given.

There are several variants of this neutralizing pattern. In some dialects, the plural is spelled out as a zero affix, in others as $-t$ and, as we have seen above, also as $-e n$ which can be realized as $-m$, $-n$, -en and $-e$. In the Frisian dialects, we find that the suffix -je can encode all plural forms. In the singular, we find the distinction between first person on the one hand and second and third on the other marked by a distinction between $-e^{5}$ and $-t$ in some dialects, in others as $-\varnothing$ versus $-t$, and as $-e$ versus $-\varnothing$ in yet others. If second person singular is marked separately, it is always encoded with the suffix $-s(t)$. The attested paradigms are given below:

\footnotetext{
${ }^{4}$ In the five measure points with zero marking throughout the singular at the French border not only the singular, but also second person plural is encoded with $\emptyset$. First and third person plural are encoded with $e n$. We can understand this pattern as the result of $-t$ deletion (cf. Goeman 1999). Second person and third person singular and second person plural used to be encoded with $-t$ and first person was already encoded with a zero affix. $T$-deletion yielded homophony between all singular forms and second person plural which in Middle Dutch were all encode with $-t$ (cf. Aalberse 2009).
}

5 Again, as in (1) and all other reported paradigms in Dutch, e stands for schwa. 
(9) a. The plural is encoded with -en

\begin{tabular}{lll}
\hline & Singular & Plural \\
1 & $-\varnothing$ & -en \\
2 & $-t /-s(t)$ & -en \\
3 & $-t$ & -en
\end{tabular}

b. The plural is encoded with $-t$

\begin{tabular}{lll}
\hline & Singular & Plural \\
1 & $-\mathrm{e}$ & $-\mathrm{t}$ \\
2 & $-\mathrm{t} / \mathrm{-st}$ & $-\mathrm{t}$ \\
3 & $-\mathrm{t}$ & $-\mathrm{t}$
\end{tabular}

c. $\quad$ The plural is encoded with $-\varnothing$

\begin{tabular}{lll}
\hline & Singular & Plural \\
1 & $-\mathrm{e}$ & $-\varnothing$ \\
2 & $-\varnothing$ & $-\varnothing$ \\
3 & $-\varnothing$ & $-\varnothing$
\end{tabular}

d. The plural is encoded with -je

\begin{tabular}{lll}
\hline & Singular & Plural \\
1 & -je & -je \\
2 & $-\mathrm{st}$ & -je \\
3 & -t & -je
\end{tabular}

Note that all paradigms are identical in their global structure; i.e. all these dialects formally distinguish between first person on the one hand, and second and third on the other (and in some cases second person singular is separately encoded), and all these dialects have uniform plural marking. The variation in these dialects comes from different Vocabulary Items. So, they all have the same rules as in (6) albeit with different phonological forms.

2.2 Potential counterexamples: absence of number marking in the context of person

In Sect. 2.1 we considered the absence of (overt) person marking. We observed that person marking is largely absent in the marked context of the plural. In line with Markedness-Triggered Neutralization, absence of person marking in the singular implies absence of person marking in the more marked plural. Out of the total number of 507 measure points described, 30 show total absence of person marking. Person is not marked in the context of the plural in 337 measure points. In this subsection we will consider possible evidence against this pattern. Is there also evidence for a pattern in which number is neutralized in the context of person? We will show that superficially some of those patterns seem to exist, but that on closer inspection, these patterns turn out to confirm the pattern illustrated above. 


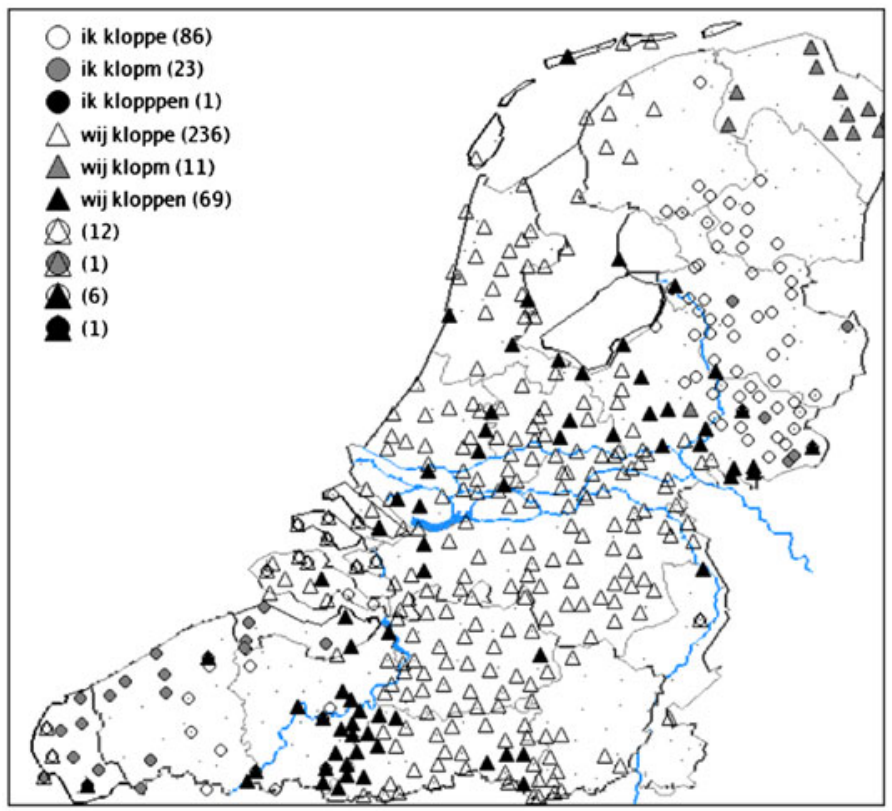

Fig. 3 First person singular and plural

In some measure points first person singular and first person plural are homophonous. This homophony is associated with the suffix $-e(n)$. Figure 3 shows the distribution of this suffix. We can see that both the association between first person singular and $-e(n)$ and first person plural and $-e(n)$ is common, but that the association of both first person singular and first person plural with the suffix $-e(n)$ is rare. We find it only in the southwest in a total number of 13 measure points.

These dialects come in two variants. In most of these dialects first person is spelled out as $-e$ (both in the singular and in the plural) whereas in one other measure point it is spelled out as $-e n$ (realized as $-m$ ). The complete paradigms are as in (10a and b) respectively:

(10) a. First person singular and plural encoded with $-e$

\begin{tabular}{lll}
\hline & Singular & Plural \\
1 & $-\mathrm{e}$ & $-\mathrm{e}$ \\
2 & $-\mathrm{t}$ & $-\mathrm{e}$ \\
3 & $-\mathrm{t}$ & $-\mathrm{e}$
\end{tabular}

b. First person singular and plural encoded with -en

\begin{tabular}{lll}
\hline & Singular & Plural \\
1 & -en & -en \\
2 & $-\mathrm{t}$ & -en \\
3 & $-\mathrm{t}$ & -en
\end{tabular}


But this syncretism in first person singular and plural is not a structural property of the paradigm. Rather, it should be interpreted as a form of accidental homophony. In Middle Dutch first person singular was encoded with $-e$ and the plural was encoded with $-e n$. The southwest of the Netherlands was the only area where word final $-e$ was retained and where word final $-n$ (following $-e$ ) was deleted, yielding superficial homophony between first person singular and the plural forms. Note that the suffix that encodes first person always also encodes all plural forms. So, our morphological analysis of the pattern in (10a) is as in (11). (11a) contains VI's and (11b) shows the same impoverishment rule as we assumed for the other Dutch dialects (see (7)):

$$
\begin{array}{llll} 
& {[+\mathrm{S}]} & \Leftrightarrow & -\mathrm{e} \\
& {[+ \text { plur }]} & \Leftrightarrow & -\mathrm{en} \\
& {[-\mathrm{S}]} & \Leftrightarrow & -\mathrm{t} \\
\text { b. }[\alpha \mathrm{S}, \beta \mathrm{U}] & \Leftrightarrow & \varnothing \quad / \text { [plural }]
\end{array}
$$

There is no single dialect with absence of number marking in the context of first person rather than neutralization of person in the context of number. Person marking in the plural is always absent and in addition we incidentally find formal overlap between first person singular and first person plural.

Whereas the number of measure points where number is neutralized in the context of first person is rather small, apparent absence of number marking in the context of second person, is more frequent. This type of neutralization is attested in 225 measure points as shown in Fig. 4a and b.

If second person singular and plural are encoded by the same form, this is associated with the suffixes $-t$, $-e n$ (representing phonological realizations as $-m$, $-e n,-n$ and $-e$ ) and $\varnothing$. In Fig. 4a dialects where all plurals are encoded by one of these suffixes are shown in combination with the appearance of these suffixes in second person singular. Out of the 38 measure points where all plurals are encoded with $-t, 21$ measure points also encode second person singular with this suffix. Out of the 252 measure points that encode all plurals with -en, 32 also encode second person singular with $-e n$. The two measure points that encode all plurals with $\varnothing$, also show this suffix in second person singular.

In Fig. 4b the measure points are shown where second person plural is encoded with a different form than first and third person plural. In these measure points first and third person plural are associated with $-e n$ (representing $-m,-e n,-n$ and $-e$ ) and second person is either encoded with $-t$ or $\varnothing$. In 163 of the 169 measure points where second person plural is encoded with $-t$, we find this affix in second person singular as well. In seven out of the fourteen measure points where second person plural is encoded with $\varnothing$, we find the suffix encoding second person singular as well. In three of these measure points we find that second person singular is encoded with $-t$. The area where second person singular is encoded with $\varnothing$ is associated with heavy $-t$-deletion (cf. Goeman 1999) and it is likely that in these three measure points second person singular and second person plural largely overlap. 

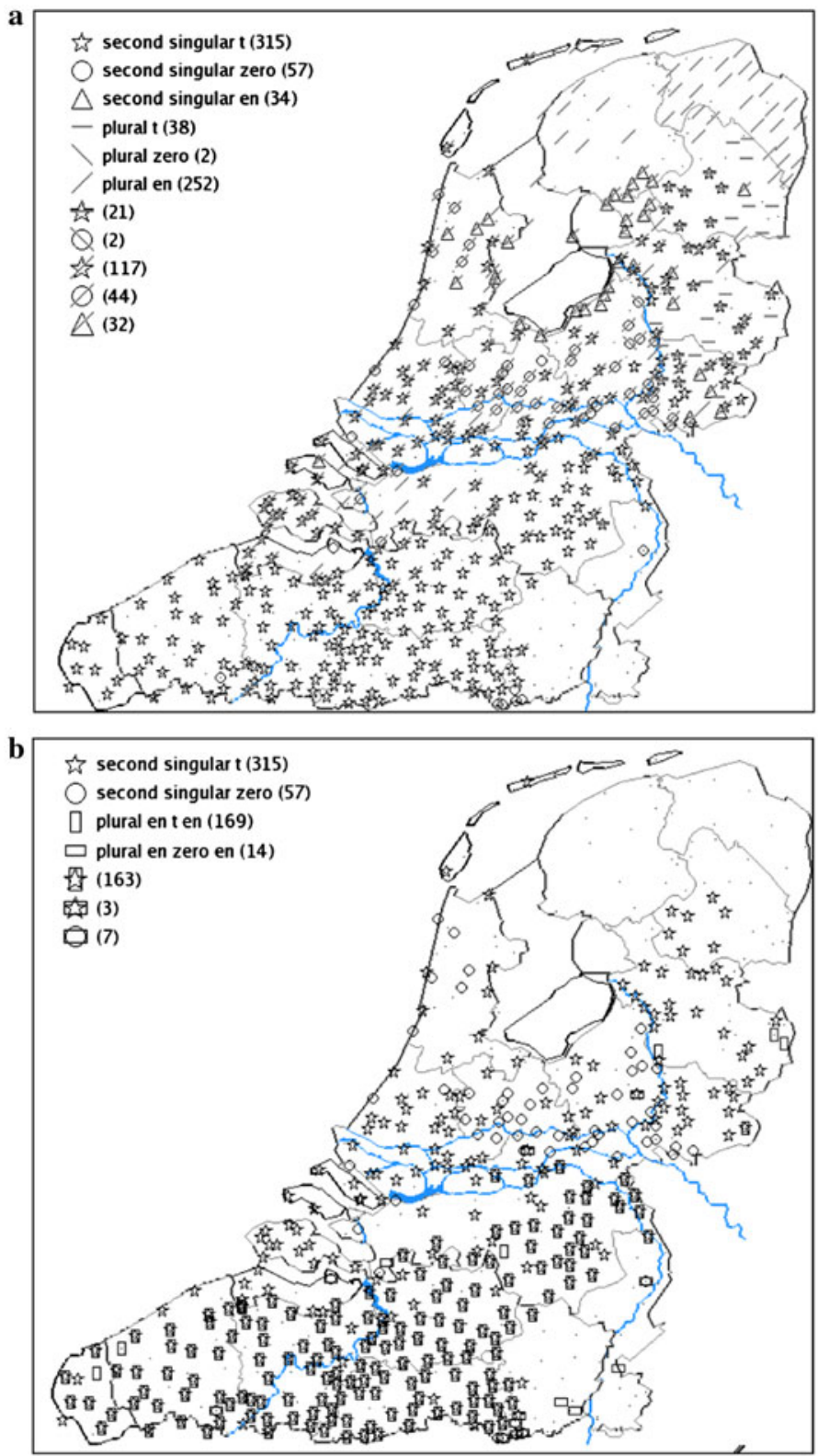

Fig. 4 a Second person singular and general plural marker. b Second person singular and specific second person plural marker

Again, dialects that display this overlap in marking between plural and singular forms all have a uniform plural marking. In that sense, these dialects thus conform to the observed pattern of person neutralization in the plural. However, since these dialects mark the plural with an affix, which happens also to be used to express a 


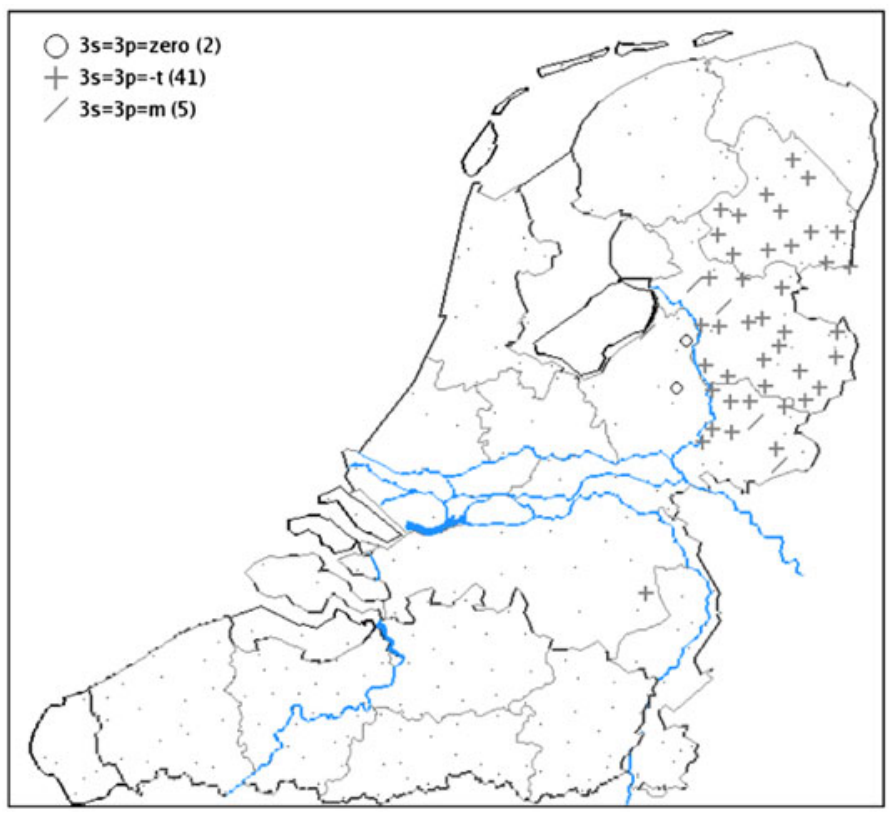

Fig. 5 Absence of number marking in the context of third person

person feature in the singular, these patterns should be analysed as incidental homophony rather than as true neutralization. Let us first consider the paradigm in (12):

(12) Second person singular and plural encoded with $-t$

\begin{tabular}{lll}
\hline & Singular & Plural \\
1 & $-\varnothing$ & $-\mathrm{t}$ \\
2 & $-\mathrm{t}$ & $-\mathrm{t}$ \\
3 & $-\mathrm{t}$ & $-\mathrm{t}$
\end{tabular}

Our analysis of this paradigm is as follows:

$$
\begin{aligned}
& \text { a. }[+\mathrm{S}] \Leftrightarrow-\varnothing \\
& {[-\mathrm{S}] \Leftrightarrow-\mathrm{t}} \\
& \text { [+plur }] \Leftrightarrow-\mathrm{t}
\end{aligned}
$$

As before, in dialects of this type the Impoverishment rule in (7) is operative.

In Fig. 5 measure points are given that lack overt marking of the distinction between third person singular and third person plural. In total, this type of neutralization is attested in 48 measure points. 
These dialects have one of the following paradigms:

a. $3^{\text {rd }}$ person: $-t$

\begin{tabular}{lll}
\hline \hline & Singular & Plural \\
\cline { 3 - 3 } 1 & $-\mathrm{e}$ & $-\mathrm{t}$ \\
2 & $-\mathrm{t}$ & $-\mathrm{t}$ \\
3 & $-\mathrm{t}$ & $-\mathrm{t}$ \\
\cline { 2 - 3 } & & \\
& &
\end{tabular}

b. $3^{\text {rd }}$ person: $-\varnothing$

Singular Plural

\begin{tabular}{|l|l|l|}
\cline { 3 - 3 } 1 & $-\mathrm{e}$ & $-\varnothing$ \\
2 & $-\varnothing$ & $-\varnothing$ \\
3 & $-\varnothing$ & $-\varnothing$ \\
\hline
\end{tabular}

c. $3^{\text {rd }}$ person: $-e n$

\begin{tabular}{lll}
\hline \hline & Singular & Plural \\
1 & -e & -en \\
2 & -en & -en \\
3 & -en & -en
\end{tabular}

This absence of person marking in the context of third person is only attested in the east of the Netherlands where all plurals are encoded with $-t$ (or $\varnothing$ after $-t$-deletion). In Fig. 2 we saw that in 18 measure points in the east the suffixes $-t$ and $-e n$ alternate throughout the plural. It is possible that this alternation was extended to the singular via a superficial analogy rule yielding the paradigm in 14c. Again, we find that absence of number marking in the context of third person is related to accidental homophony and only attested in addition to absence of person marking in the plural.

Our analysis of the pattern in $(14 \mathrm{a}, \mathrm{b}, \mathrm{c})$ is as follows:

$$
\begin{array}{lll}
{[+\mathrm{S}]} & \Leftrightarrow & -e \\
{[+ \text { plur }]} & \Leftrightarrow & -t(\text { in } 14 \mathrm{a}),-\varnothing(\text { in } 14 \mathrm{~b}),-e n(\text { in } 14 \mathrm{c}) \\
{[-\mathrm{S}]} & \Leftrightarrow & -t(\text { in } 14 \mathrm{a}),-\varnothing(\text { in } 14 \mathrm{~b}),-e n(\text { in } 14 \mathrm{c})
\end{array}
$$

These dialects are also assumed to have the impoverishment rule (7).

However, there are also a number of dialects showing absence of number marking in the second person. Two examples of this pattern are given in $(16 a, b)$ : 
a. Second person singular and plural encoded with $-\varnothing /-t$

\begin{tabular}{lll}
\hline & Singular & Plural \\
1 & $-\mathrm{e}$ & $-\mathrm{en}$ \\
2 & $-\mathrm{t} /-\varnothing$ & $-\mathrm{t} /-\varnothing$ \\
3 & $-\mathrm{t} /-\varnothing$ & $-\mathrm{en}$
\end{tabular}

b. Second person singular and plural encoded with -en

\begin{tabular}{lll}
\hline & Singular & Plural \\
1 & $-\varnothing$ & en \\
2 & - en & -en \\
3 & $-\mathrm{t}$ & en
\end{tabular}

These are the only examples showing a real lack of number marking in the context of second person. Therefore, these dialects do not conform to the impoverishment rule in (7) and need to be analyzed differently. We will come back to their proper analysis in the next section where we will also look for an explanation of the uniform plural marking that we find in the majority of the Dutch dialects.

\section{Deflection and language acquisition}

In Sect. 1 we saw that we can understand the dependency of number on person as the result from the rise of agreement: the likelihood of number marking increases with animacy. The more frequently a grammatical category is expressed in a certain context, the more likely it is to grammaticalize (cf. Bybee 1985). The observation that unmarked categories are more likely to express distinctions than marked categories can be understood in a similar way: unmarked categories are more frequently used than marked ones. Their higher frequency makes them more prone to grammaticalization processes.

In this section we will consider trends in neutralization patterns from the perspective of language acquisition and deflection. Deflection involves a reduction of the number of inflectional contrasts used in a language. In Sect. 3.1 we will look at the circumstances under which language learners decrease the number of inflectional contrasts they acquire. The hypothesis is that this reduction is systematic and that the resulting patterns follow from language acquisition strategies. In order to find out what these language acquisition strategies are, we will consider general tendencies in the neutralization of inflectional distinctions in Sect. 3.2. In Sect. 3.3 these general tendencies are related to language acquisition strategies. In Sect. 3.4 the relation between general tendencies in neutralization and the direction of person-number dependency in case of deflection is discussed.

\subsection{Deflection and language acquisition}

A first step towards an explanation of the patterns of neutralization that we have found in the Dutch and Frisian dialects is that children acquire inflectional contrasts 
in a specific order. Deflection implies a reduction of the number of acquisition steps taken. We expect loss first of contrasts that are acquired late. The question is: under what circumstances do we observe a reduction in the number of contrasts? In this subsection we will consider factors that can trigger deflection.

It is generally accepted (Pinker 1996) that inflectional contrasts are only assumed to be present by first language learners on the basis of overt evidence. Consequently, a qualitative or quantitative reduction in the input of the evidence for inflectional contrasts can slow down the acquisition process up to the point that a specific contrast is no longer acquired. This reduction in the input may be due to language internal and language external processes. We will show that the loss of person marking in the plural in Dutch results from the joint forces of both language-internal and language-external factors.

The first language external process to consider is language or dialect contact. On average, adult language learners are less successful in mastering inflection than young learners (Johnson and Newport 1991, Hyltenstam and Abrahamsson 2003; Blom et al. 2007 among many others). This may also have an effect on the acquisition, and the result of the acquisition process of the learners of the next generation. Very briefly, the idea is that if two languages are in contact with one another, there is a tendency for adults to learn the new language. This results in an increase in the number of adult learners. If adult learners do not fully acquire the target system, their language will differ at some points from the previous system. This variation will lead to differences in the input for the next generation. A less consistent input may imply less evidence for specific inflectional contrasts leading to a possible loss of such contrasts altogether. The observation that adult learners are less successful in mastering inflection predicts a correlation between the number of adult learners in a language community and deflection. Indeed, we find that the degree of language contact correlates with the degree of deflection. More language or dialect contact implies more deflection (Trudgill 1986,Weerman 1993, Kroch and Taylor 1997).

Not every language, however, is equally prone to deflection. Some inflectional paradigms pose more difficulties for language learners than others. At this point, language-internal factors may determine what kind of inflectional contrasts are especially vulnerable under these circumstances. Polišenská (2010) shows that some inflections are more vulnerable to omission than others. Typical characteristics of inflectional affixes that are prone to late emergence are those that encode multiple features, unstressed affixes, non-syllabic affixes, and infixes. Empirical studies confirm that the order of acquisition of morphemes is contingent on factors such as phonological salience of the morphemes, and a clear-cut relation between the affix and the features it encodes (e.g. Brown 1973; Slobin 1985; Bittner and Dressler 2003; Laaha and Gillis 2007).

In short, language contact increases the likelihood of deflection. Fusional systems with phonologically non-salient suffixes are most prone to deflection.

\subsection{General tendencies in the neutralization of inflectional distinctions}

In Sect. 3.1 we related deflection to a systematic reduction in the number of inflectional contrasts assumed by language learners as the result of a decrease in 
overt evidence for these inflectional contrasts. The final goal of this section is to understand the role of neutralization in the acquisition of inflection. More specifically, the goal is to understand the 'dominance' of [number] over [person] in cases of deflection. In order to reach this goal we will first look into trends in the neutralization of inflectional distinctions in this subsection. We may distinguish three different sources for these trends.

First, a general tendency in (verbal) inflection that can be grouped under what Bobaljik (2008) refers to as morpheme inventory universals. Morpheme inventory universals are implicational. There is, for example, an implicational relationship between values of inflectional categories. The relationship is formalized in (17).

\section{Morpheme inventory universal concerning feature values} value $X_{4}>$ value $X_{3}>$ value $X_{2}>$ value $X_{1}$

For example, a possible candidate for category $\mathrm{X}$ is the category number. We can associate $\mathrm{X}_{4}$ with the value trial, $\mathrm{X}_{3}$ with the value dual, $\mathrm{X}_{2}$ with the value plural and $\mathrm{X}_{1}$ with the value singular. Then, the morpheme inventory universal tells us that the presence of a trial implies the presence of a dual, and, similarly, the presence of a dual implies the presence of a plural form, etc. (see also Aikhenvald and Dixon 1998, p. 59, Harley and Ritter 2002, p. 497; Cysouw 2003, p. 309, Baerman et al. 2005, pp. 92-95). The loss of the dependent values [trial] and [dual] in Anejom that we saw in Sect. 1 corresponds with this implicational hierarchy in number values.

Second, we saw that neutralization occurs mainly in the context of marked features such as [dual] or [plural] and not in the context of an unmarked feature such as [singular]. Following Nevins (2009) we refer to this tendency to neutralize features in the context of dependent values as Markedness-Triggered Neutralization. To further illustrate the relation between markedness and neutralization, let us compare the abstract paradigms in $(18 \mathrm{a}, \mathrm{b})$.

a.

Expected: past tense neutralizes person

$\begin{array}{lll} & \text { Present } & \text { Past } \\ 1 & \text { A } & \text { D } \\ 2 & \text { B } & \text { D } \\ 3 & \text { C } & \text { D } \\ \end{array}$

b. Not expected: present tense neutralizes person

\begin{tabular}{l|l|l}
\multicolumn{1}{l|}{} & \multicolumn{1}{l}{ Present } & Past \\
1 & A \\
2 & A & D \\
3 & A & E \\
& & F
\end{tabular}


The value [past] is more marked than the value [present] (Greenberg 1966). In languages where tense is not encoded inflectionally, finite verbs receive the present tense as a default interpretation (De Hoop et al. 2004). The observation that present tense yields a default interpretation is additional support for the assumption that the present tense is an unmarked form. Following Markedness-Triggered Neutralization, we expect that the likelihood of neutralization is greater for the past tense than for the present tense.

The third tendency relates to the direction of neutralizations. The paradigm in (19) (where person neutralizes tense) is less likely to occur than the pattern in (18a) (where tense neutralizes person).

\section{Not expected: person neutralizes tense}

\begin{tabular}{lll}
\multicolumn{1}{c}{} & Present & Past \\
1 & A & A \\
2 & B & E \\
3 & C & F
\end{tabular}

This follows from a hierarchical relation between grammatical features, based on the grammatical level the feature is associated with (Aikhenvald and Dixon 1998). Features like [person] that are associated with the predicate argument are hierarchically lower than features like [tense] that are associated with the full predicate.

Pinker (1996, p. 204) suggests that the hierarchy between grammatical features can be made even more specific. He claims there is a relation between the proximity of an affix to the stem and the direction of neutralization. Therefore, let us consider what Bobaljik (2008) refers to as affix-order universals. If one compares affix ordering across languages, there is no universal linear ordering for affixes. Some affixes are, however, cross-linguistically expressed more closely to the stem than other affixes. For example, cross-linguistically, aspect is expressed closer to the stem than tense (Blansitt 1975; Julien 2000). This means that we can expect to find two morpheme orders (assuming the languages code tense and aspect): [tenseaspect-stem] or [stem-aspect-tense]. Languages that encode tense closer to the stem (aspect-tense-stem and stem-tense aspect) are not attested.

The generalization concerning the expression of aspect and tense exhibits a more general pattern, namely, that it is not possible to make linear generalizations, but that we can make typological generalizations concerning proximity to the stem. The ordering of affixes in relation to the verb stem plays a role in Bybee (1985), Cinque (1999), Julien (2002) and Rice (2000). A common feature in these studies is the hierarchical ordering of grammatical features. Typically, affix-order universals have the general form as in (20).

Affix Order

If a category $\mathrm{Y}$ occurs in the same word as category $\mathrm{X}$, then $\mathrm{X}$ is closer to the stem than $\mathrm{Y}$. 
Two affix orders are allowed by (20); [Y-X-STEM] and its mirror image [STEM-X$\mathrm{Y}]$ since, in both these sequences, $\mathrm{X}$ is closest to the stem. The sequences [X-Y$\mathrm{STEM}$ ] and its mirror image [STEM-Y-X] are not permitted since $\mathrm{Y}$ is closer to the stem than X. Pinker (1996, pp. 204-205) suggests that affix order and the direction of neutralization are related. He suggests that features expressed closer to the stem are higher on the hierarchy of functional elements than features expressed further away from the stem. Features that are higher up in the hierarchy of functional elements are likely to neutralize features that are lower on the hierarchy. Take a feature like tense. Bybee (1985, p. 35) shows that in her sample tense is expressed closer to the stem of a verb than person marking. Since tense is expressed more closely to the stem than person, it is higher up the hierarchy of functional elements than person. Since tense is higher up the hierarchy of functional elements, we predict that tense neutralizes person and not vice versa. The predicted direction of neutralization is formulated in (21).

\section{Direction of neutralization}

If $\mathrm{X}$ and $\mathrm{Y}$ are both functional categories, and $\mathrm{X}$ is a category in a position higher in the hierarchy of functional elements than $Y$, then $X$ can neutralize Y, but Y cannot neutralize X.

Since tense is expressed closer to the stem than person, and thus higher in the hierarchy of functional elements, we predict that tense neutralizes person.

The paradigm in (18a) is in line with both the direction of neutralization as described in (21) as well as with Markedness-Triggered Neutralization. Following (21), we expect neutralization of person in the context of tense and following (4), we expect that neutralization occurs in the context of marked feature values such as [past]. The paradigm in (18b) also neutralizes person in the context of tense which is the predicted direction of neutralization as formulated in (21) but it goes against (4), since the unmarked tense feature value [present] neutralizes person rather than a marked feature value. We expect neutralization to occur, only in the context of marked feature values.

\subsection{Limited paradigm splitting}

In Sect. 3.2, we focused on affix inventory universals and the direction of neutralization patterns. The goal of this subsection is to relate these generalizations about the reduction of inflectional distinctions to a parsimonious learning strategy. We follow Pinker (1996, pp. 166-208) in the assumption that paradigmatic distinctions are acquired on the basis of formal differences between variants of the same word. Learners begin with a system without inflectional distinctions. Language learners will only depart from this position if they encounter inflectional contrasts in the input. For example, if there is no evidence for the inflectional category [tense] in the input, learners will not assume this category. Learners will assume the smallest number of distinctions necessary to account for the input. A small number of formal distinctions thus corresponds to a small inventory of morphological features.

The system behind neutralization patterns can also be related to language acquisition strategies. The question is why we find systematic patterns of neutral- 
ization. Pinker (1996, pp. 203-206) relates neutralization patterns to limited paradigm splitting. Limited paradigm splitting means that if learners build an inflectional paradigm, they will build it in the most parsimonious way allowed by the input. Say that a language learner is confronted with evidence for the values [first], [second] and [third] in the category [person] and with the values [present] and [past] in the category [tense]. This creates six logical combinations, if the learner would immediately allow the maximum number of splits right away.

Now, instead of immediately allowing all possible paradigm splits, the learner only allows limited paradigm splitting. Limited paradigm splitting is guided by two factors: a hierarchy of functional elements and a markedness hierarchy. The ordering of affixes and direction of neutralization are predictable based on the hierarchy of functional elements. Instead of expressing both person and tense features, the learner will first only express the category that is highest in the hierarchy of functional elements. As we have seen, categories that are expressed close to the verb stem are higher up in the hierarchy of functional elements (20) and (21). Since [tense] is expressed closer to the stem, a learner will first express [tense] rather than [person]. If learners are confronted with evidence for the category [person], the markedness hierarchy says that the learner will split the paradigm for person marking only in the unmarked value of the category [tense], or in this case, the present tense. Thus, [person] is first expressed in the unmarked context [present]. Only if the input provides evidence for the feature [person] in the marked context [past], will the paradigm split in order to encode person marking in the past tense.

\subsection{Limited paradigm splitting and the dependency of person on number}

In Sect. 3.3 we related Markedness-Triggered Neutralization to an acquisition strategy that first limits language learners to the assumption of distinctions in unmarked contexts. In marked contexts only the feature highest up in the hierarchy of functional elements is expressed. The neutralization of [person] in the context of the [plural] in Anejom fits in with Markedness-Triggered Neutralization in the sense that we find neutralization in the marked context of the plural rather than in the unmarked singular. But it is difficult to detect a hierarchical difference between the categories [person] and [number]. The categories are both associated with the level of the predicate argument, and thus there is no hierarchical relation between the two in this sense. If we look at affix-order, this also does not show signs of a fixed hierarchical relation between the categories [person] and [number]: In most languages the person-number features are fused (Bybee 1985; Trommer 2005). Furthermore, Trommer (2005) shows that there is no fixed distance of the affixes that encode person and number to the stem of the verb in those languages that do not fuse number and person affixes.

In the case of deflection in Anejom (3) and in the case of deflection in Dutch (4), we saw that person is neutralized in the context of number. Person features are neutralized in the context of the marked plural and not neutralized in the unmarked singular. Neutralization of person in the context of number fits the more general picture of limited paradigm splitting where some features are neutralized in the context of a marked value of another feature. 
To understand why we observe the neutralization of person in the context of number in deflection, let us consider the options of limited paradigm splitting for a language learner who has evidence for (i) three person distinctions in the singular and (ii) number marking throughout the entire paradigm. Bybee (1985) shows that third person plural forms are the most frequently attested plural forms in Spanish. Since third person inflection combines not only with pronominal subjects, but also with full DP's and in impersonal constructions, it is likely that Bybee's observation can be generalized to other languages. Baerman et al. (2005) show that if person marking is lost, third person plural marking is usually generalized to first and second person plural, as was the case in Anejom and Dutch. The overgeneralization of third person plural to non-third person plural forms is also observed in studies on language acquisition (cf. Leonard et al. 2002).

Since third person is a very general and therefore frequent form, it is likely that a learner who acquires the plural is first confronted with evidence for the plural feature in third person. Now, there are two possible paths of paradigm splitting. One possibility is that number is encoded only in third person, as shown in (23). This option goes against the animacy hierarchy since third person plural marking implies plural marking on first and second person.

\begin{tabular}{|c|c|c|}
\hline & Singular & Plural \\
\hline 1 & $-\mathrm{a}$ & \\
\hline 2 & $-b$ & \\
\hline 3 & $-c$ & $-d$ \\
\hline
\end{tabular}

A second possibility is that third person plural marking is interpreted as a general plural marking as shown in (24). This second option is in line with the animacy hierarchy, which states that if number is encoded on third person, it is also encoded on first and second person.

\section{Underspecification of person in the context of number}

$\begin{array}{lll} & \text { Singular } & \text { Plural } \\ 1 & -\mathrm{b} & -\mathrm{d} \\ 2 & -\mathrm{c} & \\ 3 & -\mathrm{a} & \\ \end{array}$

The fact that [person] features neutralize in the context of number in deflection, is thus related to limited paradigm splitting in combination with the animacy hierarchy and the relative frequency (w.r.t first and second person) of third person in the input. Since third person is a frequent and general form it is acquired early relative to first and second person. Following the animacy hierarchy, the presence of number marking on third person implies number marking for first and second person. The only form of limited paradigm splitting following the animacy hierarchy is the assumption of a general plural marker like in (24). 
Now, consider a situation in which the input does not provide enough and consistent data with respect to first and second person plural forms, because of the language-external factors discussed above. Add to that the language-internal factor that the affixes to be acquired are in a phonologically weak position: they are stressless, and can be rather difficult to perceive. Under such conditions, and given the acquisition strategy just explained, loss of second person marking is a phenomenon that we may expect to occur. Under these circumstances, it is possible that this first assumption by the language learner of a general plural marker is not corrected: the general plural marker remains. This is exactly the pattern we observed in Anejom and in Dutch. ${ }^{6}$

\subsection{Patterns with person marking in the plural}

As we have seen above, there are some dialects that resist the pattern of a uniform plural. Given our explanation of the uniform plural, we should also ask ourselves why some dialects may resist this general tendency. First of all we should like to point out that our explanation is an explanation of the possibility, or even likelihood, of the uniform plural to occur, but it is not an explanation that forces these patterns to occur under all circumstances. It requires a precise mix of external factors, and language-internal factors, for the deflection pattern to occur. This explanation therefore, in itself allows some variation.

Second, the absence of a plural marker in the context of second person is more widespread than neutralization of number in the context of first and third person and it is also attested in measure points that do not have a general plural form. In total there are 225 measure points where second person singular and plural are homophonous. The homophony is not restricted to one suffix with a phonological variant, as in the case of $-e(n)$ as a marker for first person, and $-t /-\varnothing$ for third person. Second person can be encoded with $-t / \varnothing$ and $-e(n)$. Therefore, neutralization of number in the context of second person cannot be related to phonological alternations. The question is why second person deviates from first and third person.

We believe that the answer to this problem lies in another more or less languageexternal factor that interferes in this case. If we consider personal pronouns in Dutch we observe that in all measure points where second person singular is homophonous

\footnotetext{
${ }^{6}$ One of the reviewers notes that not all languages follow the pattern where the singular paradigm is richer than the plural paradigm. (S)he notes that Standard French and the Oevdalian variety of Swedish have a richer plural paradigm than the singular. Since markedness-triggered neutralization is a universal property of language acquisition, it is the direction of the neutralization we expect in case of disruption in every language, independent of the form of the affix in case of disruption in the acquisition process. However, other factors such as phonology can play a role too in deflection or the lack thereof. The French plural suffix $-o n[s]$ and $-e[z]$, for example, carry stress and are therefore salient, perhaps explaining their resistance to deflection. In other cases affixes are phonologically very similar yielding phonologically motivated homophony (Cf. Baerman et al. 2005, p. 73, fn. 20). Phonologically motivated homophony or resistance to deflection is affix specific and language specific. Paradigms like in French and Oevdalian Swedish can arise through a factor such as phonology, but the direction of the change they exhibit, namely loss of distinctions in the marked part of the paradigm, is less common (Cf. Baerman et al. 2005, p. 170).
} 
with second person plural, we also find a second person pronoun in the singular that is cognate with $g i j$, an original plural form. Gij and its form variants were originally plural forms only, and entered the singular as a polite form (cf. Aalberse 2009). In many dialects the traditional second person singular pronoun $d u$, and the suffix $-s$ it combined with, were lost in favour of the former plural form. Since second person singular is derived from the plural it is not surprising that the two forms are identical in many dialects. What is much more interesting is that in many dialects, second person singular and second person plural became dissimilar again in favour of a general plural marker in the form of -en, which implied loss of the homophony between second person singular and second person plural.

If we consider this politeness-perspective the homophony between second person singular and second plural is actually rather small. There are data available on second person marking for 537 measure points. In 131 of these measure points second person is encoded with the suffix $-s(t)$ that combines either with the traditional second person singular pronoun $d u$ or with no pronoun at all. There are 406 measure points where the second person singular pronoun is cognate with an originally plural form. We thus expect the homophony between second person singular and second person plural suffix in all 406 measure points. In reality, this homophonous pattern was lost in 189 measure points in favour of general plural marking following the pattern in (4) where the original second person plural marker $-t$ that also made its way to second person singular is replaced by the general plural marker -en in the context of the plural. The homophony between second person singular and second person plural that resulted from politeness, was instable and gave way to the pattern we expected, namely the pattern where person is neutralized in the context of the marked plural in case of deflection.

\section{Conclusion}

In this paper we have tried to argue that the, typologically unexpected, personnumber syncretism as we find it in the verbal paradigm of many Dutch dialects, is the result of a number of independent factors, some of which are language-external, others language-internal.

An important language-internal factor is the Markedness triggered neutralization (Nevins 2009). Since [plural] is the marked value of the category [number], according to this principle we expect neutralization to occur in this half of the paradigm rather than in the singular.

Second, the specific circumstances under which the loss of second person plural may occur is one of dialect contact. Adults that acquired the language as a second language in their adulthood largely determine the input for a new generation of learners.

Third, a specific learning strategy, i.e. limited paradigm splitting, in combination with the frequency of the third person as compared to the first and second person, may explain why under specific externally motivated circumstances, the third person plural form becomes the form which spreads over all persons in the plural. Since the person plural markings to be acquired are stressless and phonologically weak, these suffixes turn out to be especially vulnerable during second language acquisition (Polišenská 2010), hence their loss, and the rise of a uniform plural affix. 
Acknowledgements We would like to thank the editors of the volume, Andrew Nevins, Uli Sauerland, Jonathan Bobaljik for their valuable comments and helpful suggestions. We would also like to thank Jochen Trommer for his encouraging e-mails and remarks. Also, we thank two anonymous reviewers for their criticism and help. We thank Marc van Oostendorp for providing the most recent raw data of the Morphological Atlas of Dutch dialects.

Open Access This article is distributed under the terms of the Creative Commons Attribution Noncommercial License which permits any noncommercial use, distribution, and reproduction in any medium, provided the original author(s) and source are credited.

\section{References}

Aalberse, S. (2009). Inflectional economy and politeness. Morphology-internal and morphology-external factors in the loss of second person marking in Dutch. Utrecht: LOT-dissertation series.

Aalberse, S., \& Don, J. (2009). Syncretism in Dutch dialects. Morphology, 19(1), 3-12.

Aikhenvald, A. \& Dixon, R. M. (1998). Dependencies between Grammatical Systems. Language, 74(1), 56-80.

Baerman, M., Brown, D., \& Corbett, G. (2005). The syntax-morphology interface. A study of syncretism (Cambridge Studies in Linguistics). Cambridge: Cambridge University Press.

Barbiers, S. et al. (2006). Dynamische syntactische Atlas van de Nederlandse Dialecten. Amsterdam, Meertens Instituut. http://www.meertens.knaw.nl/sand.

Bennis, H., \& MacLean, A. (2006), Variation in verbal inflection in Dutch dialects. Morphology, 16(2), 291-312.

Bittner, D., \& Dressler, W. (2003). Development of verb inflection in first language acquisition: A crosslinguistic perspective (Studies on Language Acquisition). Berlin: Mouton De Gruyter.

Blansitt, E. (1975). Progressive aspect. Working Papers on Language Universals, 18, 1-35.

Blom, E., Polišenská D., \& Weerman, F. (2007). Effects of age on the acquisition of agreement inflection. Morphology, 16, 313-336.

Bobaljik, J. (2008). Missing persons: A case study in morphological universals. The Linguistic Review, 25(1-2), 203-230.

Brown, R. (1973). A first language. The early stages. Cambridge, MA: Harvard University Press.

Bybee, J. (1985). Morphology: A study of the relation between meaning and form. (Typological Studies in Language). Amsterdam: John Benjamins.

Cinque, G. (1999). Adverbs and functional heads. A cross-linguistic perspective. New York, Oxford: Oxford University Press.

Corbett, G. (2000). Number. (Cambridge Textbooks in Linguistics). Cambridge: Cambridge University Press.

Coveney, A. (2000). Vestiges of Nous and the 1st person plural verb in informal spoken French. Language Sciences, 22(4), 447-481.

Cysouw, M. (2003). The paradigmatic structure of person marking. Oxford: Oxford University Press.

De Hoop, H., Haverkort, M. \& van der Noort, M. (2004). Variation in form versus variation in meaning. Lingua, 114(9-10), 1071-1089.

Goeman-Taeldeman-Van Reenen Project 1980-1995. (2001) Dataset http://www.meertens.knaw.nl/gtrp. Amersterdam: Meertens Instituut.

Goeman, A. (1999). T-deletie in Nederlandse dialecten. Kwantitatieve analyse van structurele, ruimtelijke en temporele variatie. Den Haag: Holland Academic Graphics.

Greenberg, J. (1966). Language universals with special reference to feature hierarchies. The Hague: Mouton.

Halle, M. (1997). Distributed morphology: Impoverishment and fission. In B. Bruening, Y. Kang, \& M. McGinnis (Eds.), Papers at the Interface (pp. 425-449). (MIT Working papers in Linguistics 30). Cambridge: MITWPL.

Halle, M., \& Marantz, A. (1993). Distributed morphology and the pieces of inflection. In K. Hale \& S. J. Keyser (Eds.), The view from building 20 (pp. 111-176). Cambridge: MIT Press.

Harley, H., \& Ritter, E. (2002). Person and number in pronouns: A feature-geometric analysis. Language, $78(3), 482-526$.

Hyltenstam, K., \& Abrahamsson, N. (2003). Maturational constraints in SLA. In C. J. Doughty \& M. H. Long (Eds.), Handbook of second language acquisition (pp. 539-599). Malden, MA: Blackwell. 
Johnson, J. S., \& Newport, E. L. (1991). Critical period effects on universal properties of language: The status of subjacency in the acquisition of a second language, Cognition, 39(3), 215-258.

Julien, M. (2000). The syntactic representation of tense. Proceedings of ConSOLE, 8, 171-186.

Julien, M. (2002). Syntactic heads and word formation. (Oxford Studies in Comparative Syntax). Oxford: Oxford University Press.

Kerstens, J. G. (1993). The syntax of number, person and gender: A theory of phi-features. Berlin: Mouton de Gruyter.

Kroch, A., \& Taylor, A. (1997). Verb movement in old and middle english: Dialect variation and language Contact. In A. van Kemenade \& N. Vincent (Eds.), Parameters of morphosyntactic change (pp. 297-325). Cambridge: Cambridge University Press.

Laaha, S., \& Gilles, S. (2007). Typological perspectives on the acquisition of noun and verb morphology. Antwerp: University of Antwerp.

Leonard, L., Caselli, C., \& Devescovi, A. (2002). Italian children's use of verb and noun morphology during the preschool years. First Language, 22(3), 287-304.

Lynch, J. (2000). A grammar of anejom. Canberra: Australian National University.

Nevins, A. (2009). Marked triggers vs. marked targets and impoverishment of the dual. http://www. people.fas.harvard.edu/ nevins/publications.html.

Noyer, R. (1992). Features, positions and affixes in autonomous morphological structure. PhD thesis, MIT, Cambridge, MA.

Pinker, S. (1996). Language learnability and language development. With new commentary by the author. Cambridge, MA: Harvard University Press.

Polišenská, D. (2010). Dutch children's acquisition of verbal and adjectival inflection. Utrecht: LOT-dissertation series.

Rice, K. (2000). Morpheme order and semantic scope. Word formation in the Athapaskan verb. (Cambridge Studies in Linguistics). Cambridge: Cambridge University Press.

Slobin, D. (1985). The crosslinguistic study of language acquisition: The data (Vol 1). Hillsdale, NJ: Lawrence Erlbaum Associates.

Trommer, J. (2005). Distributed optimality. Diss. University of Potsdam. http://www.uni-leipzig.de/ $\sim$ jtrommer/papers/papers.html.

Trudgill, P. (1986). Dialects in contact. (Language in Society 10). Oxford: Blackwell. http://opus.kobv. de/ubp/volltexte/2005/101/.

Weerman, F. (1993). The diachronic consequences of first and second language acquisition: The change from OV to VO. Linguistics, 31(5), 903-931. 